\title{
Polytechnic Students' Mathematical Thinking Processes in Linear Algebra: A Qualitative Approach
}

\author{
Muhammad Sani Abdurrahman", Abdul Halim Abdullah",", Sharifah Osman², \\ Zakiah Mohamad Ashari ${ }^{2}$, Nurul Farhana Jumaat ${ }^{2}$, Dayana Farzeeha Ali ${ }^{2}$, Norazrena Abu Samah ${ }^{2}$ \\ ${ }^{1}$ Department of Mathematics, Waziri Umaru Federal Polytechnic, Kebbi State, Nigeria \\ ${ }^{2}$ Faculty of Social Sciences and Humanities, School of Education, Universiti Teknologi, Malaysia
}

Received May 15, 2020; Revised June 16, 2020; Accepted July 20, 2020

\begin{abstract}
Cite This Paper in the following Citation Styles
(a): [1] Muhammad Sani Abdurrahman, Abdul Halim Abdullah, Sharifah Osman, Zakiah Mohamad Ashari, Nurul Farhana Jumaat, Dayana Farzeeha Ali, Norazrena Abu Samah, "Polytechnic Students' Mathematical Thinking Processes in Linear Algebra: A Qualitative Approach," Universal Journal of Educational Research, Vol. 8, No. 9, pp. 3946 - 3957, 2020. DOI: 10.13189/ujer.2020.080919.
\end{abstract}

(b): Muhammad Sani Abdurrahman, Abdul Halim Abdullah, Sharifah Osman, Zakiah Mohamad Ashari, Nurul Farhana Jumaat, Dayana Farzeeha Ali, Norazrena Abu Samah (2020). Polytechnic Students' Mathematical Thinking Processes in Linear Algebra: A Qualitative Approach. Universal Journal of Educational Research, 8(9), 3946 - 3957. DOI: 10.13189/ujer.2020.080919.

Copyright $\subseteq 2020$ by authors, all rights reserved. Authors agree that this article remains permanently open access under the terms of the Creative Commons Attribution License 4.0 International License

\begin{abstract}
The main challenge in teaching is to build experiences that include students and promote their thinking processes required to make meaning of those experiences. Thinking is unique for human beings and is characterized as a continuous rebuilding of high-level mental abilities that are consciously developed over time to create a more sophisticated structure of knowledge. The polytechnic curriculum is generally aimed at training students to become engineering technicians as well as critical thinkers; and at the same time assume personal responsibilities in exercising technical judgments that may contribute to the needs, expectations and growth of the diverse economy of any nation. This study adopts a qualitative approach using thematic analysis to explore polytechnics students' mathematical thinking processes (MTPs) in linear algebra based on Mason's approach. The researchers interviewed seven students; and the selection of the students for the interview was based on their posttest scores previously published in our quantitative study consisting of two students who achieved the highest scores, three students who achieved moderate scores and two students who achieved the least scores. A semi structured interview was used to acquire rich and detail insight in the students' understanding with regards to their MTPs. Deductive coding method was used to generate codes and themes from the interview data as the verbatim quotes of
\end{abstract}

each student are examined. Results of this study showed development of MTPs among the students with respect to specializing, generalizing and conjecturing while convincing shows a non-significant result.

Keywords Polytechnic Students, Mathematical Thinking Processes, Linear Algebra, Qualitative Approach

\section{Introduction}

Polytechnic education is an important sub-sector of the education system which provides middle level workers for the workforce needed in the industrial and technological development of a country. The development of polytechnic education is of great importance at this time as it can be an economic diversification tool for reducing unemployment through the development of entrepreneurship. Ref [1] asserted that the primary function of polytechnic education is to train students in technical and vocational fields so that after graduation they can become self-employed and create jobs for others; leading to the awards of Certificates, National Diploma, Higher National Diploma and Advanced Professional Diploma which are relevant to the needs, expectations and growth of the diverse economy and 
industries of the nation. Nowadays, every country's future depends on the quality of education that its citizens received. The countries that have the most benefit are those with a well-educated population in the field of sciences, engineering, technology and social sciences that characterize the 21 st century [2].

One of the reason for teaching mathematics at polytechnic level is to provide and equip students with skills and knowledge that will make them self-dependent as well as to be competent to work as technicians. Different research indicates that students' low attainments in mathematics can have significant long-term consequences, affecting later school achievement, employment and future earnings [3]. In many countries, underachievement in mathematics is strongly associated with social, cultural and economic disadvantages $[4,5]$. According to [6-8], all engineering technicians must be able to grasp, either individually or under the guidance of trained engineers and scientists, the reasons and objectives for carrying out technical and managerial responsibilities; and must have personal leadership abilities and logical thinking. From the context of the education system, each individual is expected to become an effective problem solver in his real life $[9,10]$. It is critical that students are prepared with knowledge to face real-life problems in their learning situation and to find out the right solution to these problems. In addition, students are considered to be able to effectively engage with linear algebra information in order to analyze the information, transform the information and generate new ideas on contributing to the development of mathematical thinking in linear algebra [11]. However, the challenges of mathematics teaching in the 21 st century are to create experiences that engage students and support their mathematical thinking skills which will make them think independently, and also be able to make sense of their learned experiences. Students nowadays are challenged to think critically on their own, be able to use available resources at their disposal to understand ideas, and develop skills in various academic areas. Helping students to learn how to think mathematically has been identify as an important educational goal, as it is used to describe thinking that is purposeful, reasoned, and goal directed [2]. A greater role in terms of students' mathematical thinking skills is mostly played by teachers because the ability of students to think mathematically may be directly affected by the approaches employed by the teachers in delivering the mathematics instruction and learning [2]. This implies that developing student-centered learning strategies will make the teaching to be effective by promoting and improving the performance of students in the classroom.

Thinking is special to humans, such that the ability to think makes them the most evolved beings of all time in the world [12-14]. Human beings encounter several problems in their lives and try to directly solve these problems in the light of their previously acquired experiences and knowledge. In a process known as mathematical thinking, students are expected to think and solve problems using abstractions logically and make reasoning in real life problems. According to $[15,16]$, mathematical thinking becomes the first vision in terms of leaning mathematics concepts and ideas which can be used to solve both routine as well as non-routine problems. Studies conducted by [17, 18] showed that mathematical thinking is among the core of the major theories of linear algebra in scientific and technological reasonings. Thus, in terms of teaching and learning of mathematical thinking, the development of education now requires teaching strategies that emphasize students' involvement in their learning, where focus is on knowledge construction [19-21]. Therefore, to develop students' mathematical thinking skills in linear algebra, the teaching and learning should be encouraged with a constructive way of finding solution to problems rather than over dependence on the usual conventional approach which sometimes lead to learning through memorization without understanding the subject matter. Hence, for students to be able to develop their mathematical thinking skills, they need to elaborate, defend, and extend their positions, opinions, and beliefs to become active learners rather than passive recipients of information, and be able to take responsibility for their own thinking and learning.

Mathematical thinking is a dynamic process that enables people to increase the complexity of their ideas by handling and expanding their understanding [12-25]. Mathematical thinking is viewed by many researchers, mathematicians and mathematics educators as a process of extending the complexities of students' ideas which combines several mental and math-related activities such as "exemplifying, specializing, completing, deleting, correcting, comparing, sorting, organizing, changing, varying, reversing, altering, generalizing, conjecturing, explaining, justifying, verifying, convincing, and refuting" [26]. The students' ability to think mathematically and use mathematical thinking in solving linear algebra problems is important in polytechnic education as it serves as the first advanced mathematics course. Being able to use mathematical thinking in solving linear algebra problems is one of the most ultimate goal of teaching mathematics at polytechnic level, so that the students would be able to conduct mathematical investigations themselves and also identify the applicability of the mathematics learned in real world situations. Ref [27] proposed an approach that the following mathematical thinking processes must be applied by students to solve mathematical problems successfully. The first process is specializing, which refers to trying special cases by looking at examples, whereas the second process is generalizing, which considers looking for patterns and relationships between concepts. The third process is conjecturing, which predicts the relationships and results while the fourth process is convincing, which is used to find the reasons and communicate the reasons why something is true.

Meanwhile, [24] conducted a quantitative study in order 
to develop polytechnic students mathematical thinking processes in linear algebra based on Mason's approach. The findings of their study showed that there was significant difference between the mean scores of the groups on posttest. In addition, they used independent-samples t-test to further study the differences on students' mathematical thinking processes. Results from their study showed development of mathematical thinking processes and learning among the students with respect to specializing, generalizing and conjecturing while convincing shows a non-significant difference. Therefore, this study will use a qualitative approach to explore polytechnics students' mathematical thinking processes in linear algebra.

\section{Methodology}

A qualitative research method has been adopted in this study using thematic analysis approach. Qualitative research is viewed by [28] as an exploratory study that provides versatility and independence in exploring the phenomena under study so as to channel natural curiosity. According to [29], Qualitative study examines phenomena in their natural environment, trying to make sense or explaining on the basis of the students' experience or meaning.

The study employed a purposive sampling technique; although there are differences in purposive sampling technique as it can be executed using different approaches [28]. The posttest scores of the study of [24] becomes the basis for the interview selection in this study. The researchers selected seven students and invited them to be interviewed to explore their mathematical thinking processes. The selected students are two students who achieved the highest scores, three students who achieved moderate scores and two students who achieved the least scores [30-34].

The research instrument used for the purpose of gathering data in this study is a semi structured interview in order to acquire rich and detail insight on the students' understanding with regards to their mathematical thinking processes. The semi structured interview is guided by an interview protocol which is a tool for extracting direct data from participants regarding their details of experience and reflection of meaning [33], [35]. It is also an informal grouping of topics and questions that the interviewer will ask in different ways for different participants [36, 37]. The purpose of having the interview guide is to help the researcher to focus on the topics prepared as well as tailor their questions to the interview context without constraining them to a particular format. Ref [30] stated that researchers should remain neutral and should not share opinions in the conduct of the interview to avoid biases. The interviewer should be genuinely open to the participants' responses and at the same time be knowledgeable in the research topic in order to link the interview data to the theory. Moreover, the researcher should be aware of the procedures and questions formed, as well as the participants' non-verbal cues, such as expression and body language.

Before the commencement of the interview, the researchers followed research ethics by providing a set of principles that assist them in conducting an ethically sounded study through obtaining students consent as well as assigning code to each participant in order to keep their identity confidential. Each student was interviewed for at least 30 minutes and the interview was conducted on $6 \& 7 / 08 / 2019$ and was held in Room 7, Centre for Continue Education (CCE) in a polytechnic in Kebbi State so as to minimize disturbances as well as create a comfortable environment.

\section{Result and Analysis}

Seven students were invited for interview to explore their mathematical thinking processes. The data was recorded, transcribed and analyzed using thematic analysis. Deductive coding method was used to generate codes and themes from the interview data as the verbatim quotes of each student are examined. Ref [38] stated that deductive codes are normally used in qualitative research where the researchers are able to anticipate or predict the kinds of data and themes that will emerge from the data. The questions of the interview were analyzed by identifying themes as shown in Table 1. The themes identified from the analysis of the conversation formed the basis of analyzing the students' mathematical thinking processes. 
Table 1. Students' comments on the type of mathematical thinking processes they learn

\begin{tabular}{|c|c|c|c|}
\hline $\begin{array}{l}\text { Interviewee } \\
\text { Identity }\end{array}$ & Verbatim quotes & Codes & Theme \\
\hline \multirow{4}{*}{$\begin{array}{c}1 \\
\text { EXG015 }\end{array}$} & $\begin{array}{l}\text { (i). "I can try solving other examples with the help of, errr with the help and guidance } \\
\text { of the learning material". }\end{array}$ & Specializing & \multirow{4}{*}{ Specializing } \\
\hline & $\begin{array}{l}\text { (ii). "I can say Cramer's formula .... They are accordingly representing the } \\
\text { determinant of the given question, determinant of } x \text {, determinant of } y \text { and determinant } \\
\text { of } z \text { ". }\end{array}$ & $\begin{array}{l}\text { Specializing } \\
\text { Generalizing }\end{array}$ & \\
\hline & $\begin{array}{l}\text { (iii). "This form of ammm, matrix represent Gaussi, ummmm .... Aaa, this name, } \\
\text { Gausy method. I think the name is Gaussian method. First of all, the first aammm row } \\
\text { will not be changed, while there is changing of rows, you know ...... What I mean is } \\
\text { second and third row will be multiplied by a whole number, not zero Sir. Then you add } \\
\text { the first and second rows to row one, to have row four and row five. You also repeat } \\
\text { the same in row five to have row six". }\end{array}$ & $\begin{array}{l}\text { Generalizing } \\
\text { Conjecturing }\end{array}$ & \\
\hline & $\begin{array}{l}\text { (iv). "I think when the values of "a" is equal to zero, then it is linearly independence } \\
\text { and if the "a" is not equal to eemm .. zero then is linear dependence". }\end{array}$ & Specializing & \\
\hline \multirow{5}{*}{$\begin{array}{c}2 \\
\text { EXG018 }\end{array}$} & $\begin{array}{l}\text { (i). "I can solve linear algebra examples, by looking at the materials given. I can also } \\
\text { look for relationship and predict their outcome". }\end{array}$ & $\begin{array}{l}\text { Specializing } \\
\text { Generalizing } \\
\text { Conjecturing }\end{array}$ & \multirow[t]{2}{*}{ Specializing } \\
\hline & $\begin{array}{l}\text { (ii). "This is determinant method Sir, or method of ammm ... solving linear equation } \\
\text { using determinant method". }\end{array}$ & Specializing & \\
\hline & $\begin{array}{l}\text { (iii). "The symbols represent the determinant of } \mathrm{A}, \mathrm{x}, \mathrm{y} \text { and } \mathrm{z} \text { respectively". } \\
\text { "Determinant of 'A' is the determinant of the given matrix while } \mathrm{x}, \mathrm{y} \text { and } \mathrm{z} \text { are the } \\
\text { determinant of matrix } \mathrm{x}, \mathrm{y} \text { and } \mathrm{z} \text { ". }\end{array}$ & $\begin{array}{l}\text { Generalizing } \\
\text { Generalizing }\end{array}$ & Generalizing \\
\hline & $\begin{array}{l}\text { (iv). "This is known as row reduction that is what } \mathrm{R} 1, \mathrm{R} 2 \text { and } \mathrm{Rn} \text { means rows". } \\
\text { "Multiply eeemmmm, a row by a number that is not zero, then umm ..., adding row } \\
\text { two and row three with row one to have the remaining rows, until you ..." "You will } \\
\text { do that until eemm .. until you have a triangle of zero numbers by the down corner of } \\
\text { the matrix. Then you you, .. you solve for } \mathrm{x}, \mathrm{y}, \mathrm{z} \text { ". }\end{array}$ & Conjecturing & \multirow[t]{2}{*}{ Conjecturing } \\
\hline & $\begin{array}{l}\text { (v). "If the scalar "a" is equal to zero then the linear combination becomes linearly } \\
\text { independence whereas if "a" is not equal to zero then the combination becomes } \\
\text { linearly dependence". }\end{array}$ & Specializing & \\
\hline \multirow{4}{*}{$\begin{array}{c}3 \\
\text { EXG027 }\end{array}$} & $\begin{array}{l}\text { (i). "I can find solution to a given question and explain the steps involved in it using } \\
\text { similar examples". }\end{array}$ & Specializing & \multirow{4}{*}{$\begin{array}{l}\text { Specializing } \\
\text { Generalizing }\end{array}$} \\
\hline & $\begin{array}{l}\text { (ii). "It has about three names Sir. Cramer's rule or matrix inversion method or } \\
\text { solution of linear equation using determinant method. And the symbols represent } \\
\text { determinant of a given matrix i.e. determinant of A, determinant of aamm x, y and z } \\
\text { respectively". }\end{array}$ & $\begin{array}{l}\text { Specializing } \\
\text { Generalizing }\end{array}$ & \\
\hline & $\begin{array}{l}\text { (iii). "It represents Gaussian elimination method Sir. The first row will be left } \\
\text { untouched as a constant, you will multiply row two and three with a number that } \\
\text { when ... when you add or subtract the rows from row one it will make their first } \\
\text { numbers to be zero. So, these two new rows now become row four and five. Then you } \\
\text { repeat the same thing to the second number of row five to also make it zero to have } \\
\text { another new row which is row six. Then from there you find the value of z from row } \\
\text { six, then you substitute the value of } z \text { from row five and you also substitute y and z } \\
\text { from row one to have". }\end{array}$ & $\begin{array}{l}\text { Generalizing } \\
\text { Conjecturing }\end{array}$ & \\
\hline & $\begin{array}{l}\text { (iv). "A mapping is described as linear transformation if }(1) \mathrm{T}(\mathrm{u}+\mathrm{v})=\mathrm{T}(\mathrm{u})+\mathrm{T}(\mathrm{v}) \text { if } \mathrm{u} \\
\text { and } \mathrm{v} \text { are in } \mathrm{V} \text { under addition, then }(2) \mathrm{T}(\mathrm{kv})=\mathrm{kT}(\mathrm{v}) \text { but if } \mathrm{k} \text { is not equal to zero under } \\
\text { scalar multiplication". }\end{array}$ & Specializing & \\
\hline \multirow{4}{*}{$\begin{array}{c}4 \\
\text { EXG021 }\end{array}$} & $\begin{array}{l}\text { (i). "I am confident, that I can use the linear algebra peer tutoring to solve similar } \\
\text { examples". }\end{array}$ & Specializing & \multirow{4}{*}{ Specializing } \\
\hline & $\begin{array}{l}\text { (ii). "Determinant method Sir. They represent determinants of matrix A, x, y and } \mathrm{z} \\
\text { Sir". }\end{array}$ & $\begin{array}{l}\text { Specializing } \\
\text { Generalizing }\end{array}$ & \\
\hline & $\begin{array}{l}\text { (iii). "It represents reduction of row. It can be described as reduction of row two and } \\
\text { row three until the left bottom corner becomes zero, until you have only one number } \\
\text { before the equality sign in the last row that will be used to find the unknown". }\end{array}$ & Generalizing & \\
\hline & $\begin{array}{l}\text { (iv). "If the values of "a" are not zero then is linear dependence while if the values of } \\
\text { "a" are equal to zero then it is linearly independence". }\end{array}$ & Specializing & \\
\hline
\end{tabular}


Table 1 continued

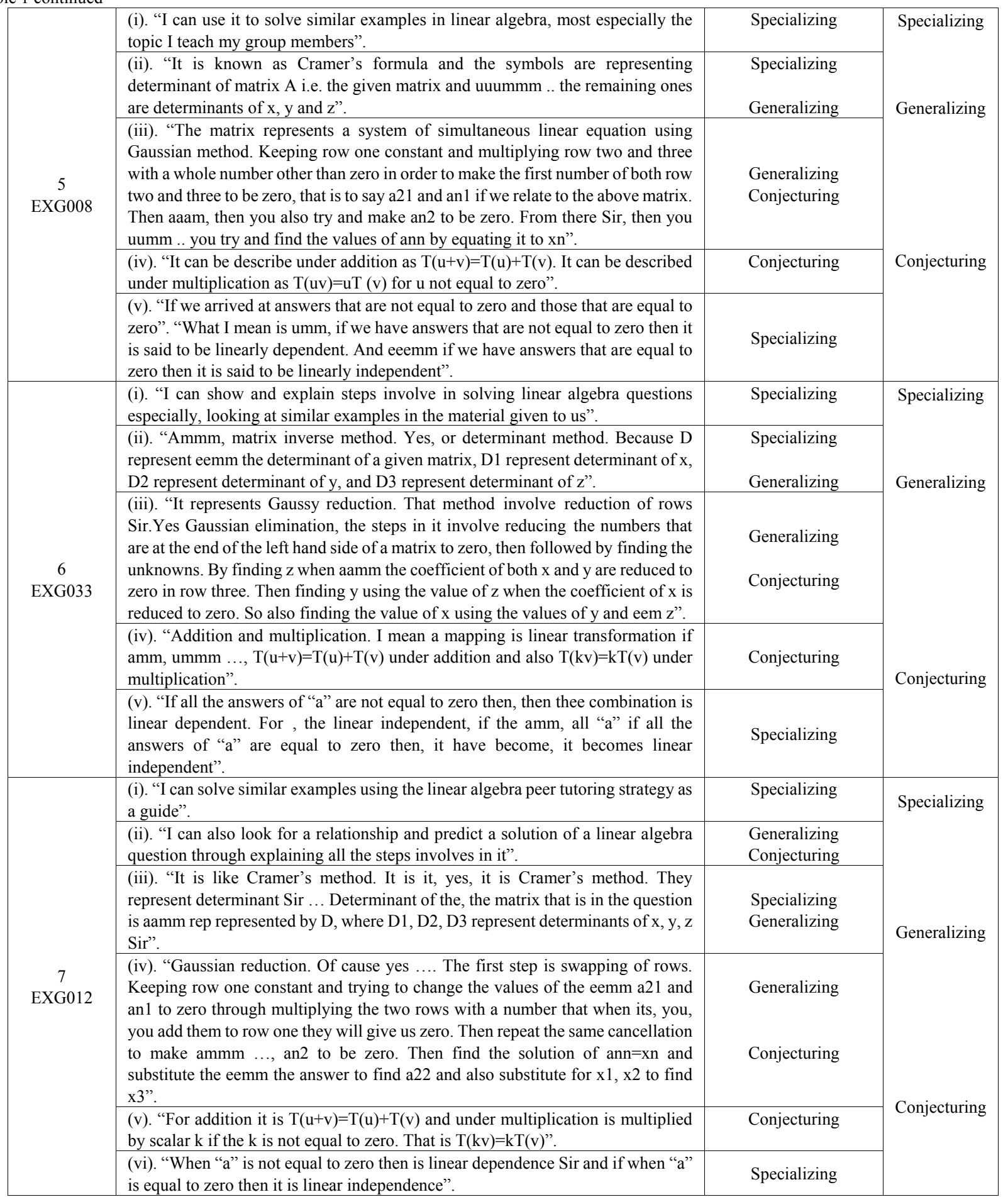


The result of Table 1 shows an astonishing outcome as it demonstrated three out of the four mathematical thinking processes. The findings shows a significant difference in the mathematical thinking processes of specializing, generalizing, and conjecturing without demonstrating any element of convincing. The students' comments appeared to be positive even though one of the mathematical thinking processes was not achieved. Besides, majority of the students were able to respond to the questions posed to them, except in the case of question [iv(d)] (refer to Appendix A) whereby some of them did not attempt it while others gave an incorrect response. Some of the comments about the question were that "to be sincere sir, aaaa ... I don't know; I think this can be true Sir when zero vector is equal to zero," which shows an absence of convincing in their mathematical thinking processes.

\section{Discussion}

The outcomes from the students' verbatim quotes (see Table 1) of the interview analysis complement that of the quantitative analysis in the study of [24] as the students were not able to achieve the final mathematical thinking process (convincing) which shows a totally different result of non-significant differences. This means that, specializing, generalizing, and conjecturing were the successful mathematical thinking processes in this study as evident in the study of [24] where the Cohen's $d$ values for the test appeared to have an effect size that is large in the difference of mean $[39,40]$. The results are in line with the findings of $[41,42]$ whom characterized mathematical thinking as a way to improve students' understanding and expand their mastery level of mathematics problems. The analysis of the findings in Table 1 revealed a positive result of a significant difference in the first three mathematical thinking processes (specializing, generalizing, and conjecturing) with a non-significant outcome in the last mathematical thinking process (convincing). This may be attributed to the fact that convincing is associated to an in-depth examination of trying to establish and justify why something is true. The studies of [27], [41], [43] argued that the first three mathematical thinking processes can be achieve if the specialization process is properly designed through a useful conjecturing, then it can be helpful in making generalization. Thus, the results in this qualitative analysis may be attributed to what [44] calls "the notion of a monitor." Ref [44] claimed that convincing is not merely a question of verification in justifying the claim, but it is worth adding the notion of a monitor. The monitor serves as an internal opponent who drives beyond complacent acceptance, doubts and claims, challenges assumptions already made, and attempts to negotiate meanings in the best possible way in the circumstances.

Moreover, when the students were asked (using some linear algebra prompt and questions) about the type of mathematical thinking processes they learn, they responded correctly to the first question prompted to them. As a result, it is clear that they demonstrated element of specializing when they were asked about the method of solving simultaneous linear equation that uses the formula $\mathrm{x}=\Delta_{1} / \Delta, \mathrm{y}=\Delta_{2} / \Delta$ and $\mathrm{z}=\Delta_{3} / \Delta ;$ and they also demonstrated generalizing while given their feedback on what the symbols $\Delta, \Delta_{1}, \Delta_{2}, \Delta_{3}$ represent. They further responded to the type of system of linear equation the given matrix represents in the second question which indicates that they were able to demonstrate the concept of generalizing as all students recognized the linear equation to be Gaussian elimination or row reduction method. However, their responses demonstrated that they achieved the concept of conjecturing in this question as they were all able to describe all the possible steps involved in finding solution to the given matrix. From the feedback given by the students in the third question, four of them were able to respond to the question correctly, two gave an incorrect response whereas one did not attempt answering the question saying that "I'm not sure. I don't know Sir". Their responses clearly show that four students had demonstrated the concept of conjecturing in this question while the remaining three did not. Surprisingly, none of the students shows any element of convincing in the fifth question as five of the students did not attempt the question while the remaining two provided an incorrect answer. This may be because convincing is associated with in-depth examination of trying to find out and communicate reasons why something is true. Finally, all the students were able to respond to question six that $\mathrm{a}_{1} \mathrm{v}_{1}+\mathrm{a}_{2} \mathrm{v}_{2}+\mathrm{a}_{3} \mathrm{v}_{3}+\cdots+$ $a_{n} v_{n}=0$ is linearly dependence if $a \neq 0$ and is linearly independence if $\mathrm{a}=0$. As a result, it is clear that they demonstrated element of specializing in their verbatim quotes with regards to linear combination. From the responses demonstrated by the students, it is clear that three out of the four mathematical thinking processes where significant leading to a conclusion that: specializing, generalizing and conjecturing were the successful mathematical thinking processes during this study.

The findings in this study is similar to that of [43], [45-48], who found out that supporting specialization and generalization activities will stimulate students' to use their own powers in making sense of mathematics as well as predict relationships. This form of interaction makes up a greater part of mathematical thinking, which could be attributed to students' encounter with new mathematical concepts or problems after specialization (which is the first stage suggested when students are stuck and are unable to continue with a question), formulation is built in their minds, which seems to be the starting point for using generalization which can also be expanded to remember prior information as well as linking and predicting new relevant concepts. The results of this study show that students are consistently learning new concepts or deal with problems while relating it with other similar examples 
(specialization); explore patterns or interactions between concepts and try to articulate them mathematically (generalizing); predict relationships and results through making some judgments on differences and similarities between examples to find the appropriate way to solve the problem (conjecturing). This finding varies from previous studies conducted by [43], [49-54] who found out that students should discuss their ideas and convey them directly to others in order to convince themselves, convince a friend who asks friendly questions and then convince an enemy.

In a nutshell, Table 1 showed three out of four mathematical thinking processes that are demonstrated by the students during the conduct of their interview. From seven students' verbatim quotes, the process of specializing happens to be the most frequent identified code achieved which appeared in twenty-one different places based on their responses. This is in line with the study of [55] who argued that a successful mathematical thinker is able to demonstrate specializing process through trying special cases while looking at previous examples as well can easily connect new concepts to familiar one through seeking explanation when others came up with new ideas. Thereafter, generalizing process appeared as the second most frequent identified code from the students' verbatim quotes which are coded in sixteen different places. This shows that students are able to look for patterns and relationship to a given question and also know what representation is appropriate to use and when to make use of it. Furthermore from the students' verbatim quotes, conjecturing was coded in twelve different places which makes it the third frequent identified code. This may be attributed to the fact that conjecturing is expected to be one of the mathematical thinking traits a successful mathematical thinker should possesses in the study of [55]; which leads to predicting a range of reasoning methods and proof by students through several informal ways of representing problem and its solutions using a range of representation in expressing his/her thinking.

\section{Conclusions}

Most of the polytechnic curriculum depends heavily on mathematics; and the success of the students depends strongly on their ability to connect mathematics with the technical and vocational fields $[56,57]$. Linear algebra is one of the unavoidable advanced courses in mathematics that many students encountered at both polytechnic and university levels; therefore, one of the most essential thing that would support and improve students learning in it is to promote their thinking skills. Teaching and learning of polytechnic linear algebra should be encouraged with a constructive way of finding solution to problems rather than over dependence on the usual conventional approach which sometimes lead to learning through memorization without understanding the subject matter. Most of the conventional teaching and learning in colleges emphasize the development of knowledge rather than thinking skills [58][59]; although different researches shows that the important of thinking skills in educating students is to cope with the rapidly changing world. For students to be able to develop their thinking skills, they need to elaborate, defend, and extend their positions, opinions, and beliefs so as to become active learners rather than passive recipients of information, making them taking responsibility for their own thinking and learning.

Moreover, this study looked into mathematical thinking processes of polytechnic students in learning linear algebra through a qualitative approach which contributes to the body of knowledge by providing useful empirical information for polytechnic curriculum planners, mathematics educators and students. In developing polytechnic students' problem solving skills, there is need for the incorporation of mathematical thinking processes with real life application. The information provided helps students understand the importance and relevance of thinking skills in solving linear algebra problems. This could help curriculum planners and mathematics educators to strengthen polytechnic instructions by having a curriculum that closely reflects the real-life application.

In order to develop students' mathematical thinking processes, linear algebra questions were prompted in the interview protocol. The interview was recorded, transcribed and analyzed using thematic analysis. Deductive coding method was used to generate codes and themes from the interview data as the verbatim quotes of each student are examined. Students' comments on the mathematical thinking processes show that they have demonstrated some elements of specializing, generalizing, and conjecturing without demonstrating any element of convincing. Based on the themes generated from the students' verbatim quotes, it is therefore concluded that students have developed their mathematical thinking processes.

\section{Recommendations for Future Research}

From the findings of this study, the following recommendations were made for future research:

i) The findings of this research show the need for further research on the development of mathematical thinking in linear algebra among polytechnic students. It would be of great interest and provide deeper insight if several polytechnics and a wider range of participants from the same program level are used over a longer period of time. This may lead to the achievement of a more robust result with regards to all the mathematical thinking processes.

ii) The main purpose of polytechnic education is to train 
students in technical and vocational fields to provide middle-level workers with the required manpower in a country's industrial and technological growth. It would be of great opportunity to achieve this if a closer alliance is made with regards to the application of linear algebra concepts to real life situation (like traffics flow, electrical network, and stress analysis of a truss). This indicates that more research needs to be done to help bridge this gap between the linear algebra taught in our polytechnic classrooms and the real-life scenario.

iii) The developed learning strategy in this research was confined to linear algebra learning. Results from the research have shown that it has the potential to develop students' mathematical thinking processes with respect to Mason's approach. Therefore, research should be conducted to incorporate technology into the learning instruction to see its effectiveness. It would also be useful if another learning instruction will be developed to incorporate technology into linear algebra classroom using other mathematical thinking perspectives (such as Tall's model and Schoenfeld's model) to respond to the learning environment of the $21^{\text {st }}$ century.

\section{Acknowledgement}

The authors would like to thank the Ministry of Education and Universiti Teknologi Malaysia for their financial support. This work was supported by the UTMShine Grant no. Q.J130000.2413.09G34

\section{Appendix A. Semi Structured Interview Protocol}

The purpose of this interview protocol is to guide/remind the researchers on the steps to be followed during the interview session.

Research Title: Polytechnic Students' Mathematical Thinking Processes in Linear Algebra: A Qualitative Approach.

\section{Interview Details}

Date: $\quad 6 \& 7 / 08 / 2019$

Time: $\quad 10 \mathrm{am}-1 \mathrm{pm}$

Interviewer: The Researcher(s)

Interviewee: Name/Student Identity

\section{Steps}

1. The interviewer introduced himself to the interviewee.

2. The interviewer informed the interviewee about the:

i. $\quad$ Purpose and benefit of the study to the interviewee.

ii. Participant and sources of data being collected.

iii. Ways to protect the confidentiality of the interviewee.

iv. Duration of the interview session.

v. Audio/voice recording throughout the interview session.

3. Guide the interviewee to read and sign the consent form.

4. Turn on the audio/voice recorder and test it.

5. Probe a question that will capture the attention of the interviewee and make him/her comfortable.

6. Proceed with the questions:

i. What is your experience in using the linear algebra peer tutoring strategy (LAPTS)?

ii. What do you feel during the LAPTS intervention?

iii. Did the LAPTS helps you in understanding the topics covered?

iv. What mathematical thinking processes do you know and which of them do you learn using the LAPTS? 


\begin{tabular}{|c|c|c|}
\hline No. & Prompt and Questions & $\begin{array}{c}\text { Mathematical Thinking } \\
\text { Processes (MTPs) }\end{array}$ \\
\hline iv(a) & $\begin{array}{l}\text { Which of the methods of solving simultaneous linear equation uses } \mathrm{x}=\Delta_{1} / \Delta, \mathrm{y}=\Delta_{2} / \Delta \text { and } \\
\mathrm{z}=\Delta_{3} / \Delta \text {; and explain to me why is called that? } \\
\text { Tell me what } \Delta, \Delta_{1}, \Delta_{2}, \Delta_{3} \text { represents? }\end{array}$ & $\begin{array}{l}\text { Specializing } \\
\text { Generalizing }\end{array}$ \\
\hline $\operatorname{iv}(b)$ & $\begin{array}{l}\text { What type of system of linear equation do a row-by-column } n \times n \text { matrix represent and } \\
\text { explain the steps involved? } \\
\text { Describe the possible steps involved in finding solution to the given matrix. }\end{array}$ & $\begin{array}{l}\text { Generalizing } \\
\text { Conjecturing }\end{array}$ \\
\hline $\operatorname{iv}(c)$ & What are the conditions that described a mapping $\mathrm{T}: \mathrm{V} \rightarrow \mathrm{U}$ to be called linear transformation? & Conjecturing \\
\hline $\operatorname{iv}(d)$ & $\begin{array}{l}\text { Consider } \mathrm{R} \text { to be a field of real numbers and } \mathrm{V} \text { as a } 3 \text {-dimensional space } \mathrm{R}^{3} \text { under addition and } \\
\text { scalar multiplication. How did you think this can be true? }\end{array}$ & Convincing \\
\hline $\operatorname{iv}(e)$ & $\begin{array}{l}\text { If a linear combination of a simultaneous linear equation is } a_{1} v_{1}+a_{2} v_{2}+a_{3} v_{3}+\cdots+a_{n} v_{n}= \\
0 \text {, what makes it to be linearly dependence or linearly independence? }\end{array}$ & Specializing \\
\hline
\end{tabular}

v. Will you use the LAPTS in other mathematics questions?

7. Play back the recorded audio and request the interviewee to reflect on his/her thoughts while answering the questions.

8. Take note of every detail, such as body language, facial expression etc.

9. Thank the interviewee for his/her cooperation and participation, as well as assure them of the confidentiality of the activity.

10. Turn off the audio/voice recorder.

\title{
Appendix B. Students Consent Form
}

\author{
Polytechnic Students' Mathematical Thinking Processes in Linear Algebra: A Qualitative Approach \\ Email: abdurrahman@graduate.utm.my
}

Instruction: Please read carefully and ask any question you may have before agreeing to take part in this study. You are free to ask any questions or concerns regarding your right as a subject in this study. The researchers can as well be reached through the provided email above.

Purpose of the study: This research aims to develop polytechnic students' mathematical thinking in linear algebra through qualitative approach. By knowing the key factors, a learning strategy (LAPTS) was designed by the researchers in order to promote students' mathematical thinking processes. Consequently, the researchers will identify the effectiveness of the learning strategy as well as how it assists students in developing their mathematical thinking processes in a linear algebra classroom.

Procedure: If you are to be in this study, we will like to conduct an interview with you for a period of about 30 minutes; and the interview will be recorded but with your permission/consent. We are going to ask you five questions about your experience in using the developed learning strategy (LAPTS). This is not a test, but rather it's to help us understand your thoughts or comments during the LAPTS intervention.

Risks and Benefits: There are no known risks associated with participation in this study. Participation in this study will involve no costs or payments to you but it may give you a chance to share your thoughts, feelings and views. You may benefit from participating in this study by receiving additional assistance from a peer tutor, which may increase retention and mastery or you may be assigned as tutee, which may increase you in confidence and help to reinforce material.

Confidentiality of Records: Your personal information will NOT be revealed to the third party. In any sort of report that this research will be made public, be rest assured that any information that will make it possible to identify you will not be revealed. Research records will be kept in a locked file; only the researchers will have access to the records even though a transcriptionist will be used to transcribe the oral recording. Interview will only be recorded with your written permission/consent. The audio record tapes as well as transcripts will become the property of the study and will be immediately destroyed after finishing the research. 
Participation in this Study: Participation in this study is completely voluntary. Please feel free to say as much or as little as you want and you can decide not to answer any question, or to stop the interview any time you want. You are entitle of withdrawing your consent any time you wish to, as well as discontinue participating in the study or activity without prejudice.

Statement of Consent: I certify that I have read the above information, and have received satisfactory answers to my inquiries concerning the study procedures and other matters. I have been told of the confidentiality of information collected for this study.

Name \& Signature of Student:

Date:

$\mathrm{I}$, , with Admission No: also agree to participate in one or more electronically recorded interview(s) for this study. I understand that such interview(s) and related materials will be kept completely anonymous, and that the results of this study may be published in an academic journal or book. Date: Date:

\section{REFERENCES}

[1] I. S. Jahun. The Roles and Contributions of Nigerian Polytechnics in the Development of Surveying and Geo-informatics Education; Issues, Prospects and Challenges: A Global Perspectives. FIG Working Week: Helsinki, Finland, May 29-June 2, 2017.

[2] B. S. Umar. A Cognitive Analysis of Problem-Based Learning in Teaching Mathematics at Senior Secondary School Level. A PhD Thesis Submitted to Usmanu Danfodiyo University Sokoto, 2014.

[3] S. Papadakis, M. Kalogiannakis, N. Zaranis. Comparing Tablets and PCs in Teaching Mathematics: An Attempt to Improve Mathematics Competence in Early Childhood Education. Preschool and Primary Education; 4(2), 241-253, 2016.

[4] S. Papadakis, M. Kalogiannakis, N. Zaranis. The Effectiveness of Computer and Tablet Assisted Intervention in Early Childhood Students' Understanding of Numbers. An Empirical Study Conducted in Greece. Education and Information Technologies; 23(5), 1849-1871, 2018.

[5] S. Papadakis, M. Kalogiannakis, N. Zaranis. Improving Mathematics Teaching in Kindergarten with Realistic Mathematical Education. Early Childhood Education Journal; 45(3), 369-378, 2016.

[6] S. Hemlin, C. M. Allwood, B. Martin, M. D. Mumford. Creativity and Leadership in Science, Technology and Innovation. Abingdon UK: Routledge, 2014.

[7] E. R. Khairullina, L. Y. Makhotkina, A. V. Kiryakova, V. V. Baranov, O. G. Maksimova, E. G. Khrisanova. The Real and the Ideal Engineer-Technologist in the view of Employers and Educators. International Review of Management and Marketing; 6(1), 2016.

[8] K. A. Stroud, D. J. Booth. Engineering Mathematics. Palgrave: Macmillan, 2013.
[9] C. Chin, L. G. Chia. Problem Based Learning using Students' Questions to Drive Knowledge Construction. Journal of Science Education; 88(5), 707-727, 2014.

[10] J. T. Walker, S. P. Lofton. Effect of Problem Based Learning Curriculum on Students' Perceptions of Self-directed Learning. Issues in Educational Research, 13, University of Mississipi Medical Centre, 2003.

[11] K. E. Stanovich, R. F. West. On the Failure of Cognitive Ability to Predict My-side and One-sided Thinking Biases. Thinking and Reasoning; 14(2), 129-167, 2008.

[12] D. Bok. Our Underachieving Colleges: A Candid Look at How Much College Students Learn and why they should be Learning More. Princeton, NJ: Princeton University Press, 2006.

[13] L. Elder, R. Paul. Critical Thinking: Thinking to Some Purpose. Journal of Developmental Education; 25(1), 40-47, 2001.

[14] P. A. Facione. Critical Thinking: What It Is and Why It Counts. California CA: The California Academic Press, 2013.

[15] S. Saragih, E. Napitupulu. Developing Student-Centered Learning Model to Improve High Order Mathematical Thinking Ability. International Education Studies; 8(6), 104-112, 2015.

[16] Z. Karadag. Analyzing Students' Mathematical Thinking in Technology Supported Environments. A PhD Thesis Submitted to University of Toronto, 2009.

[17] A. Musa. A Systematic Attempt to Establishing the Fear and Poor Performance of Students Linear Algebra. A paper presented at the $48^{\text {rd }}$ Annual Conference of Mathematical Association of Nigeria, held at University of Nigeria, Nsuka, 2015.

[18] A. K. Yahaya. Application of Linear Algebra in everyday Life. A Paper Presented at National Mathematical Centre (NMC) supported by Petroleum Technology Development Fund (PTDF). Workshop for Tertiary Institution Lecturers at Abuja, 17 $7^{\text {th }}-22^{\text {nd }}$ May, 2014. 
[19] A. Bourne. Development of the Academic Performance Commitment Matrix (APCM): Understanding the Effects of Motivation and an Engineering Mathematics Curricular Intervention on Student Self-Efficacy and Success in Engineering, 2014.

[20] J. Herrington, T. C. Reeves, R. Oliver. Authentic Learning Environments. Handbook of Research on Educational Communications and Technology (pp. 401-412): Springer, 2014.

[21] R. Semil. Enhancing Thinking Skills in the Classroom. Human and Social Sciences Journal; 1(1), 28-36, 2006.

[22] F. Mansoor, M. Pezeshki. Manipulating Critical Thinking Skills in Test Taking. International Journal of Education; 4(1), 153-160, 2012.

[23] J. Mason, J. S. Wilder. Designing and Using Mathematical Tasks. St Albans UK: Tarquin Publications, 2006.

[24] S. A. Muhammad, A. H. Abdullah, S. Osman. Developing Mathematical Thinking among Polytechnic Students in Linear Algebra through Peer Tutoring Strategy. Journal of Advanced Research in Dynamical \& Control Systems; 12(3), 423-434, 2020. DOI: 10.5373/JARDCS/V12I3/20201210

[25] M. Y. Yudariah, A. Roselainy. Teaching Engineering Students to Think Mathematically. Paper Presented at the Conference on Engineering Education, Kuala Lumpur, $14^{\text {th }}$ $-15^{\text {th }}$ December, 2004.

[26] F. A. Sean. Mathematical Thinking: from Cacophony to Consensus. A PhD Thesis Submitted to the Graduate School of Education. Kent State University College, 2012.

[27] J. Mason, L. Burton, K. Stacey. Thinking Mathematically $\left(2^{\text {nd }}\right.$ Ed.). Edinburgh: Pearson Education Limited, 2010.

[28] J. Corbin, A. Strauss. Basics of Qualitative Research: Techniques and Procedures for Developing Grounded Theory (3rd Ed.). Thousand Oaks, CA: SAGE, 2008.

[29] S. Osman, M. S. Abu, S. B. Mohammad, M. B. Mokhtar. Identifying Pertinent Elements of Critical Thinking and Mathematical Thinking Used in Civil Engineering Practice in Relation to Engineering Education. The Qualitative Report; 21(2), 212-227, 2016. Retrieved October 2019 from http://nsuworks.nova.edu/tqr/vol21/iss2/4.

[30] J. W. Creswell. Educational Research Planning, Conducting and Evaluating Quantitative and Qualitative Research $\left(4^{\mathrm{th}}\right.$ Ed.). Boston, M. A: Pearson Education Inc., 2012.

[31] L. R. Gay, P. Airasian. Educational Research: Competencies for Analysis and Applications. NJ: Pearson Education, Inc., 2003.

[32] K. F. Punch. Introduction to Research Methods in Education. London: Sage Publications, 2009.

[33] I. Seidman. Interviewing as Qualitative Research: A Guide for Researchers in Education and the Social Sciences. New York, NY: Teachers College Press, 2006.

[34] D. Silverman. Interpreting Qualitative Data. (3 ${ }^{\text {rd }}$ Ed.). London: SAGE Publishing Inc., 2006.

[35] S. E. Rabionet. How I Learned to Design and Conduct Semi-Structured Interviews: An Ongoing and Continuous Journey. The Qualitative Report; 16(2), 563-578, 2011.
[36] T. R. Lindlof, B. C. Tylor. Qualitative Communication Research Methods. Thousand Oaks, LA: SAGE Publication Inc., 2002.

[37] D. Thomas. A General Inductive Approach for Analyzing Qualitative Evaluation Data. American Journal of Evaluation; 27(2), 237-246, 2006.

[38] Y. P. Chua. Mastering Research Statistics. Selangor, Malaysia Sdn. Bhd: McGraw-Hill Education, 2013.

[39] J. Cohen. Quantitative Methods in Psychology: A Power Primer. Psychological Bulletin; 112(1), 155-159, 1992.

[40] J. Cohen. Statistical Power Analysis for the Behavioral Sciences. Hillsdale, NJ: Erlbaum, 1998.

[41] N. Hashemi, M. S. Abu, H. Kashefi, M. Mokhtar. Designing Learning Strategy to Improve Undergraduate Students' Problem Solving in Derivatives and Integrals: A Conceptual Framework. Eurasia Journal of Mathematics, Science \& Technology Education; 11(2), 227-238, 2015.

[42] A. Roselainy. Changing My Own and My Students' Attitudes to Calculus through Working on Mathematical Thinking. PhD Thesis. Open University, UK, 2008.

[43] F. Zeynivannezhad. Mathematical Thinking in Differential Equations through a Computer Algebra System. A PhD Thesis Submitted to the Faculty of Education, Universiti Teknologi Malaysia, 2014.

[44] A. H. Schoenfeld. Reflections on Doing and Teaching Mathematics. In A. H. Schoenfeld (Ed.). Mathematical Thinking and Problem Solving (pp. 53-75). Hillsdale, NJ: Lawrence Erlbaum Associates, Inc., 1994.

[45] M. Badger, C. J. Sangwin, T. O. Hawkes, R. Burn, J. Mason, S. Pope. Teaching Problem-Solving in Undergraduate Mathematics. Technical Report, 2012.

[46] S. O. Karamzadeh. Generalization. Incredible Results in Mathematics. Ahvaz, Iran: University of Shahid Chamran Press, 2000.

[47] H. Kashefi. Mathematical Thinking in Multivariable Calculus through Blended Learning. A PhD Thesis Submitted to the Faculty of Education, Universiti Teknologi Malaysia, 2012.

[48] K. Stacey. What is Mathematical Thinking and Why is it Important. Progress Report of the APEC Project: Collaborative Studies on Innovations for Teaching and Learning Mathematics in Different Cultures (II), Lesson Study focusing on Mathematical Thinking, 2012.

[49] P. Drijvers. Learning Algebra in a Computer Algebra Environment. International Journal for Technology in Mathematics Education; 11(3), 49-61, 2005.

[50] R. B. Ferri. Mathematical Thinking Styles and their Influence on Teaching and Learning Mathematics. $12^{\text {th }}$ International Congress on Mathematical Education. COEX, Seoul, Korea, 2012.

[51] J. D. Katz. Developing Mathematical Thinking: A Guide to Rethinking the Mathematics Classroom. Lanham, Maryland: Rowman \& Littlefield, 2014.

[52] Z. Lavicza. Factors Influencing the Integration of Computer Algebra Systems into University-Level Mathematics 
Education. International Journal for Technology in Mathematics Education; 14(3), 121-130, 2007.

[53] N. Marshall, C. Buteau, D. H. Jarvis, Z. Lavicza. Do Mathematicians Integrate Computer Algebra Systems in University Teaching? Comparing a Literature Review to an International Survey Study. Computers \& Education; 58(1), 423-434, 2012.

[54] C. Rasmussen, M. Zandieh, K. King, A. Teppo. Advancing Mathematical Activity: A Practice-Oriented View of Advanced Mathematical Thinking. Mathematical Thinking and Learning; 7(1), 51-73, 2005.

[55] S. Toni. Five Processes of Mathematical Thinking. Summative Projects for MA Degree, submitted to Department of Teaching, Learning, and Teacher Education University of Nebraska-Lincoln, 2008. http://digitalcommo ns.unl.edu/mathmidsummative/38.
[56] E. Darlington, J. Bowyer. The Mathematics Needs of Higher Education. Mathematics Today; 52(1), 9, 2016.

[57] B. Loch, J. Lamborn. How to make Mathematics Relevant to First-Year Engineering Students: Perceptions of Students on Student-Produced Resources. International Journal of Mathematical Education in Science and Technology; 47(1), 29-44, 2016.

[58] T. W. Chuen. Development and Evaluation of a Web-Based Learning System Based on Learning Object Design and Generative Learning to Improve Higher-Order Thinking Skills and Learning. A PhD Thesis Submitted to the Faculty of Education, Universiti Teknologi Malaysia, 2006.

[59] N.S.A. Alhassora,, M.S. Abu \& A.H. Abdullah. Inculcating higher-order thinking skills in mathematics: Why is it so hard? Man in India, 97 (13), 51-62, 2017 